\title{
HUNTINGTON'S DISEASE AND STEROID HORMONE RECEPTORS
}

\author{
Radka Molikova, Marcela Bezdickova, Ondrej David, Linda Bebarova
}

\author{
a Department of Anatomy, Faculty of Medicine and Dentistry, Palacky University Olomouc, Czech Republic \\ e-mail:molikovaradka@yahoo.co.uk
}

Received: March 29, 2007; Accepted (with revision): May 10, 2007

Key words: Huntington's disease (HD)/Steroid hormone receptors (SHR)/Clinical picture

Background: Steroid hormone receptors constitute a special group of receptors having a wide range of efficiency and distribution in the body. Androgen and estrogen receptors, and their expression in the body, are linked with attributes such as reproduction control and sexual behaviour, but their relation with behavioural models, perception, memory and stress remain unclear to date.

Purpose: In this project we aim to focus on monitoring the expressive influence of steroid hormone receptors on embryonic tissues and subsequently, expand our study to include the expression on adult tissues such as the CNS and to monitor the developmental aspects and relations pertaining to neurodegenerative disorders, such as Huntington's disease.

Material and Methods: We shall rely on immuno-histochemistry, immuno-fluorescence and RT-PCR methods for detecting steroid hormone receptors and Huntingtin-associated protein 1 in the embryonic and adult tissue.

Conclusion: Mapping the expression of steroid receptors during development represents an essential step in the quest for further studies and monitoring of the expression in adult tissues.

\section{INTRODUCTION}

Huntington's Disease (HD) is an inherited, autosomal dominant, neurodegenerative disorder characterized by progressive motor, psychiatric and cognitive symptoms. The principal causative factor is repetition of an expanded trinucleotide CAG in the Huntingtin gene on chromosome 4 (4p16.3). The incidence of HD in the territories of Europe and the Americas is currently estimated at 1:15.000(ref. ${ }^{1}$ ). The mutation character was identified in 1993 as a consequence of multiplication of CAG triplet above 39 repetitions. Clinically, HD in its typical form is manifested by the classic clinical triad of: motive, cognitive and psychiatric afflictions ${ }^{18}$.

The set of motive afflictions comprise typical choreic dyskinesia and disturbance in voluntary movements; whereas cognitive afflictions are clinically manifested by progressive and advanced dementia of predominantly subcortical type, and psychiatric impairments exhibited in the clinical picture as behavioural changes, hypersexuality, personality disorder, affection disorder and more rarely as psychotic phenomena. It is to be borne in mind that cognitive disorders may manifest as early as 5 years prior to the appearance of motive impairments. Among the pathophysiological and degenerative changes of somewhat moderate intensity, the striate spiny neurons have been implicated; such cells are known to induce GABAdescribed degenerative changes in the neocortex. The significance and function of normal as well as mutagen- ous Huntingtin protein (htt) is currently the subject of intensive study ${ }^{11,15,18}$.

Our study aims to focus on determining the role of a group of steroid receptors, mainly the estrogen hormone receptors (ER), in Huntington's Disease. ER expression in the brain has a significant influence in reproduction control, but the significance of these hormone receptors is also merited in the psychic, behavioural and conduct aspects of an individual. Of the two isoform ER types located on two separate genes - $\mathrm{ER} \alpha$ isoform on chromosome 6 (6q25.1) highly expressed in the mammary gland, ovary, liver and ER $\beta$ located on chromosome 14 (14q22-24) mainly expressed in the GIT ${ }^{4,17}$, our study mainly focuses on $\mathrm{ER} \alpha$ as the preliminary step in the investigation.

More recent studies refer to the fact that these isoforms can have distinct functional significance in the light of the fact that $\mathrm{ER} \alpha$ and $\beta$ are expressed in many tissues including the CNS (namely in the hypothalamus, hippocampus and the cortex) where the precise location and function in relation to memory, behaviour and conduct remain unclear, or rather more precisely not specified to date. Given the function and broad scope of activities of both $\mathrm{ER} \alpha$ and $\beta$, inclusive of the fact that they play a significant role in the CNS as mentioned above, we remain confident of establishing a definite correlation between Huntington's Disease and the estrogen hormone receptors since the latter have an established role in cognition, behaviour and memory $8,9,13,12$. 

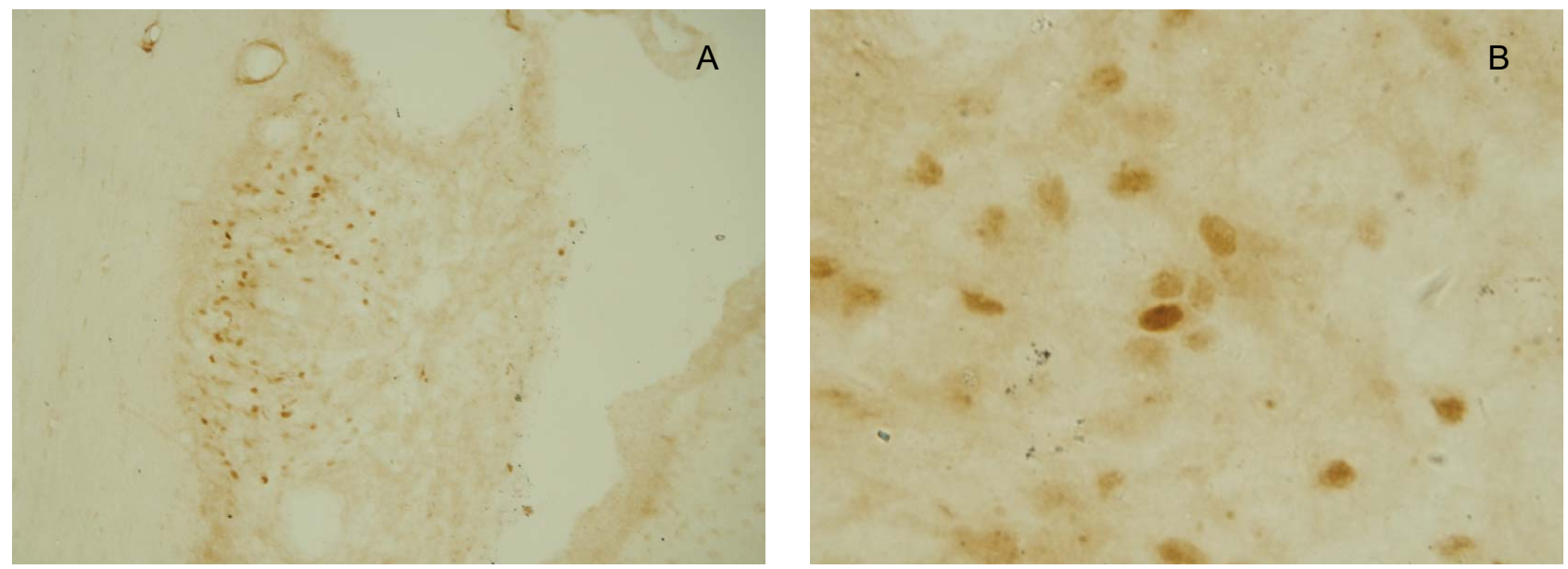

Fig. 1. Immuno-histochemistry detection of $E R$ by $A B C$ methods in mus musculus subfornical organ. Dilution 1:600. Magnification A) 100x B) 400x.

\section{AIM}

The aim of this long-term study is to focus on monitoring SHR expression in embryonic and adult tissues, namely the CNS, inclusive of monitoring the developmental aspects and the associated normal and aberrant htt; furthermore, to distinguish the pathways of SHR involvement in behavioural, cognitive and memory modifications. Our effort also extends to studying the mechanisms by which SHR mediates behaviour, cognition and memory, inclusive of the particular segment of the brain where increased and/or decreased SHR expression is exhibited. During the course of the above, we shall also be able to render a comparison of the mediating mechanisms and biological functions of SHR in the brain and its potential relation to Huntington's Disease.

\section{MATERIALS AND METHODS}

The first part of the long-term study was divided into the phase of SHR mapping and Huntingtin-associated protein 1 (HAP1) in embryonic as well as adult brain tissue, and further on the construction of plasmid which will be utilised at a later stage for SHR and aberrant Huntintin protein expression.

To map SHR and HAP1 expression in the brain, immuno-histochemistry $\mathrm{ABC}$ methods were used in the neocortex in 1:400 dilution and immuno-fluorescence in 1:600, including RT PCR. For the possibility of increasing or reducing SHR expression, the first phase comprised of plasmid pEGFP-C2-ER $\alpha$ (6499bp) construction; the correctness of which was verified by standard electrophoresis and sequencing. The expression function was verified by transfection in cell line HEK 293, which under normal circumstances does not exprimate isoform ER $\alpha$. After 48 hours of transfection, ER $\alpha$ expression was verified by immuno-histochemistry on cell line. In order to secure accurate function of pEGFP-C2-ER $\alpha$, DAPI detection was conducted to ascertain cytoplasmic and/or nuclear activity expressions.

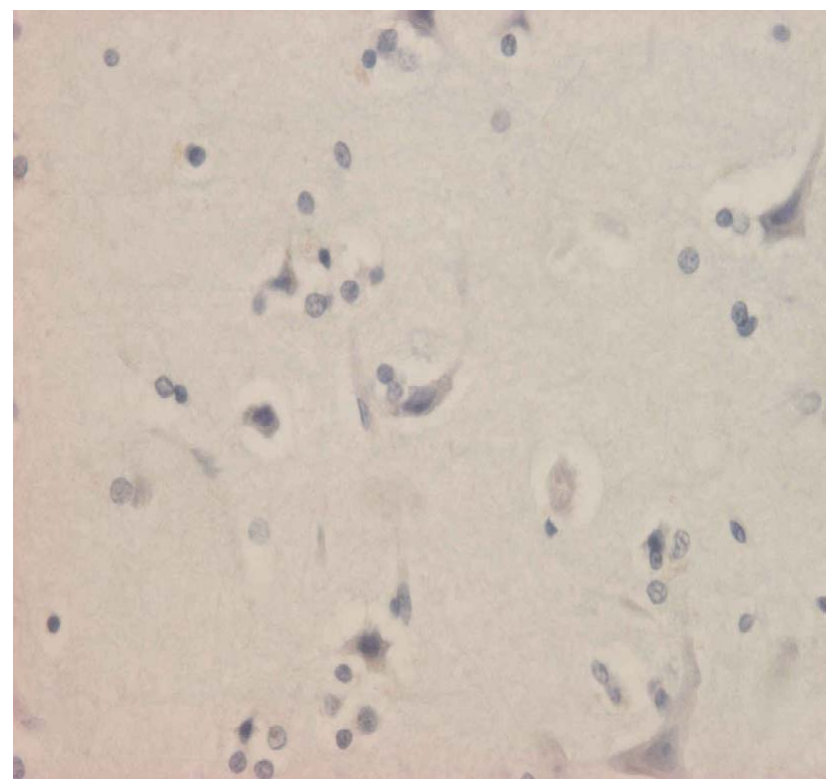

Fig. 2. Immuno-histochemistry two-stage detection of ER in precentral gyrus in human tissue only with positive cytoplasmic detection. Magnification 500x.

\section{RESULTS}

\section{Immuno-histochemistry}

Following analysis of the specimen profiles, we ascertained ER expression in the hypothalamic area of mus musculus as control and for positive results the cytoplasmic positive response in areas $\mathrm{S} 1 \mathrm{Tr}$ and $\mathrm{S} 1 \mathrm{BF}$, inclusive of positive cytoplasmic and nuclear activity in the SFO region. (Fig. 1a, b) The areas RSA and S2 represented regions where the results were not absolutely and clearly positive. It is to be noted that we approached interpreting these results as positive in a very cautious manner and supplemented our findings by RT from the neocortical areas of RSA, S2 and RSA, S2, which also came out as positive ${ }^{16}$. Another cytoplasmic positive detection was 

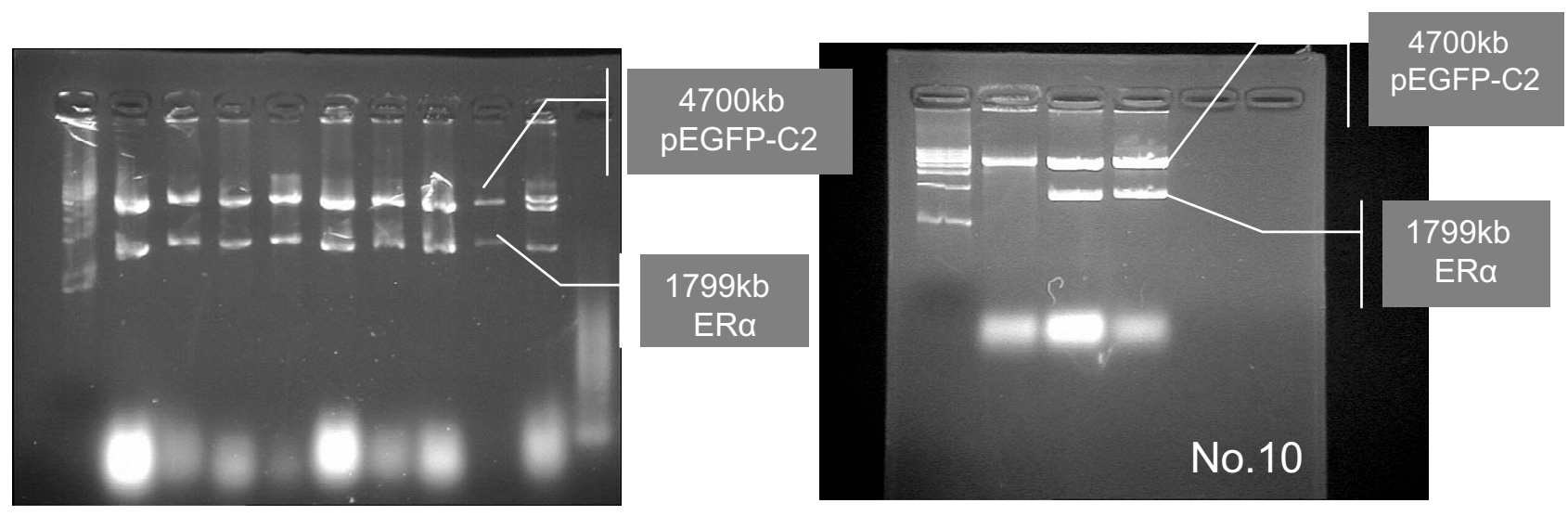

A

B

Fig 3. A) Electrophoresis of digested pEGFP-C2-ER $\alpha$.

B) Control electrophoresis of digested pEGFP-C2-ER $\alpha$ No.10.
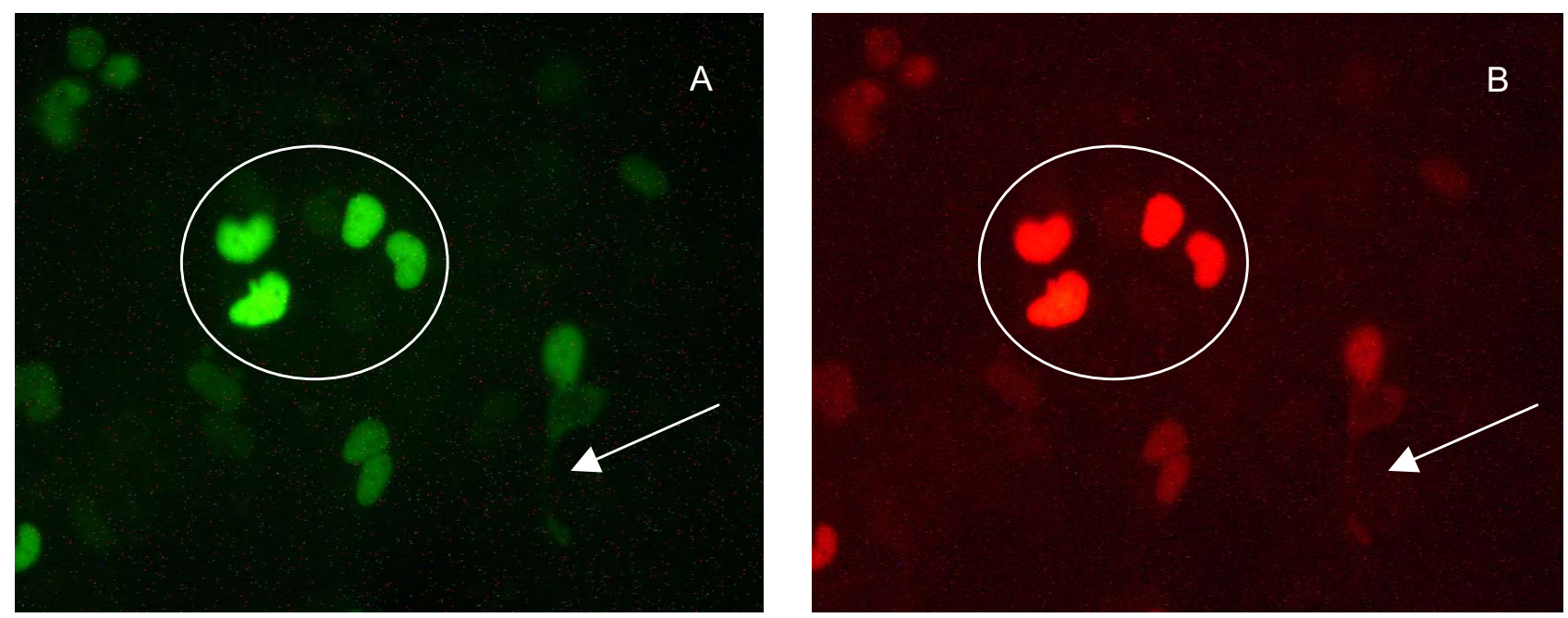

Fig. 4. A) Transfection of HEK 293 by pEGFP-C2-ER $\alpha$ after 48 hours. B) Immuno-fluorescence control expression of ER alpha in transfected HEK 293; dilution $1: 400$.
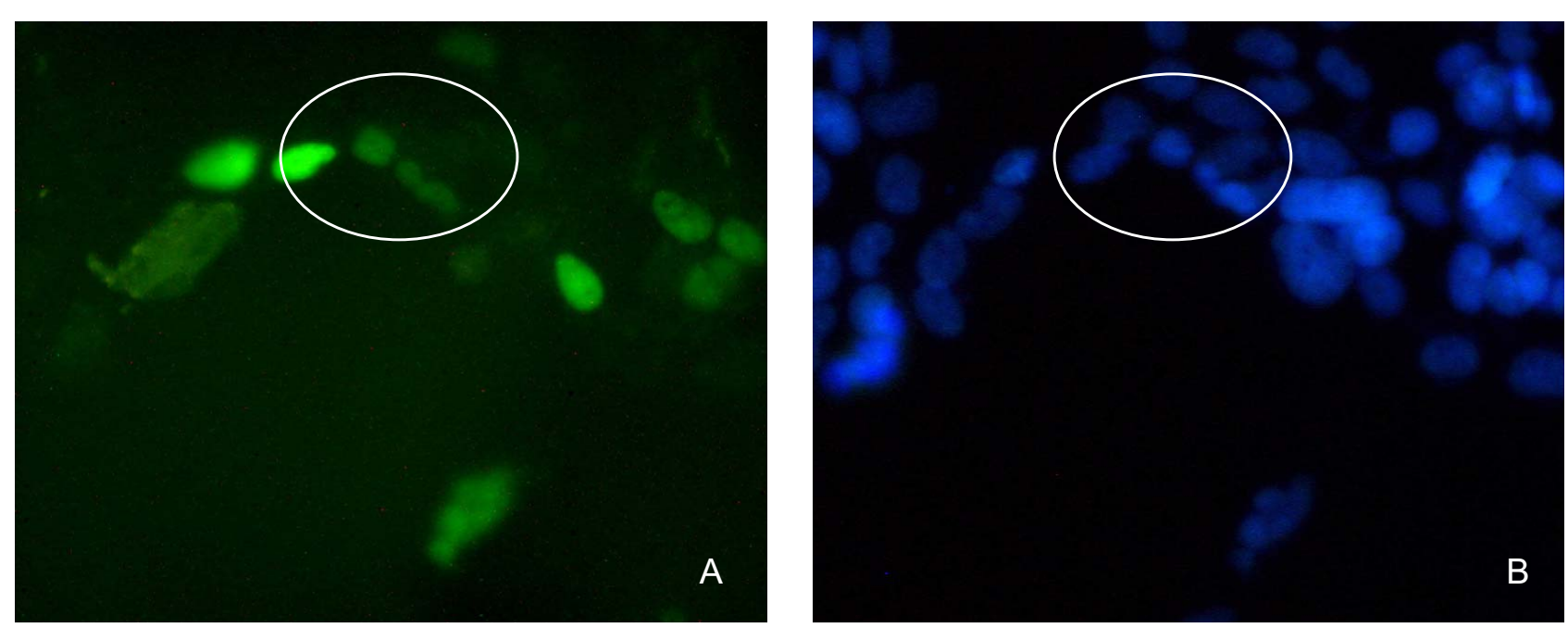

Fig. 5. A) Transfection of HEK 293 by pEGFP-C2-Er $\alpha$ after 48 hours. B) Detection of nuclear activity through DAPI. 
proved in the adult human tissue of the precentral gyrus through the method of two-stage immuno-histochemistry. (Fig. 2) Necropsy was 3.5 hours post mortem.

\section{$R T$ and $P C R$}

A plasmid pEGFP-C2-ER $\alpha$ was constructed with verification of correct construction and sequencing for mutation detection (Fig. 3) and expression function by immuno-fluorescence in cell line HEK 293. (Fig. 4 a, b) Following detection of nuclear activity through DAPI, we ascertained nuclear and weak cytoplasmic positivity - marked with arrow. In terms of the current phase of our study, we can state that a plasmid suitable for expression of ER isoform alpha is ready. (Fig. $5 \mathrm{a}, \mathrm{b}$ ) In the next phase, we will construct a plasmid suitable for ER isoform beta, AR expression and the plasmid for creating a HD mouse model subject to the permission by GMO.

\section{DISCUSSION}

Huntington's Disease, as an inherited, autosomal dominant and neurodegenerative disease, owes its clinical picture to a set of conditions caused by increased number of CAG repeats in the huntingtin gene on chromosome 4. Early in the progression of HD, motor changes include mild chorea, abnormal muscle stretch reflexes, and diminished rapid alternating movements. Marshall ${ }^{15}$ describes the cognitive manifestations early in the course of the disorder, and they primarily consist of abnormalities in information progression, cognitive flexibility, and memory retrieval ${ }^{15,18}$.

These neurological symptoms are apparently associated with nuclear accumulation of mutant huntingtin protein and its effect on gene expression. Normal huntingtin protein is a cytoplasmic protein and is also associated with synaptic vesicles. Li demonstrated that mutant htt may interact with synaptic vesicle membrane proteins or proteins associated with vesicles in axonal terminals. One of these interacting proteins may be Huntingtin-associated protein 1 (HAP1) $)^{3,11,20}$.

Steroid hormone receptors are a special type of receptors because of their localisation in the cytoplasm or nucleus of eukaryotic cells. Recent sensitive binding studies have shown the presence of ER in neocortex cells, where their function remains vague. However, the hypothesis that their involvement in mediation of estrogen influence on sexual behaviour ${ }^{6,10}$ is gaining strength.

The fact that HD presents with a varied clinical picture prompted us to study the pathways and functions of steroid hormone receptors in vitro and mainly on HD model in animal. As we know, HD mouse model was compiled and as stipulated by $\mathrm{Li}^{11}$, we know that studies comprising HD mouse models provide compelling evidence to the fact that the N-terminal fragments of mutant Huntingtin protein(htt) with expanded glutamine repeat (82Q or 150Q) "cause neurological symptoms resembling some of the clinical features of HD"2,11,14. By constructing plasmid pEGFP-C2-ER $\alpha$ and others we would like to utilise the potential cooperation of SHR on HD for the purposes of highlighting the potential and prospective methods of assisting in remedying the behavioural, cognitive and memory deficiencies found in HD.

\section{LIST OF ABBREVIATIONS}

DAPI 4'6'-diamino-2-phenylindole dihydrochloride

GABA gama-aminobutyric acid

HAP 1 huntingtin-associated protein

HEK 293 human embryonic kidney cell

htt aberrant huntingtin

ER estrogen receptor

HD Huntington disease

PCR polymerase chain reaction

RSA retrosplenial agranular cortex

RT reverse transcription

S1Tr primary somatosensory cortex , trunk region (gyrus postcentralis)

S1BF primary somatosensory cortex, Barrel field

S2 secondary somatosensory cortex

SHR steroid hormone receptors

SFO subfornical organ

\section{ACKNOWLEDGEMENT}

This research is supported by the Internal grant of Faculty of Medicine and Dentistry Palacký University 9111007139/2006 and under the scholarship of Ministry of Education Czech Republic and Ministry of Education P. R. of China in Tongji Medical College, Wuhan. All work with GMO was conducted in Tongji Medical College, China through the kind auspices of the relevant Chinese authorities.

I would like to thank my tutor Prof. LI He, for his devoted guidance and assistance in my research; Dr. Shan Shan Huang for her expert advice and perpetual enthusiasm, with which she guided me through the entire duration of my studies.

\section{REFERENCES}

1. Al-Jared LN, Harper PS, Krawczak M, Palmer SR. The frequency of inherited disorders database: Prevalence of Huntington disease. Community Genet, 2001; 4:148-157.

2. Davies SW, Turmaine M, Cozens BA, DiFiglia M et al. Formation of neuronal intranuclear inclusions underlies the neurological dysfunction in mice transgenic for the HD mutation. Cell, 1997; 90:537-548.

3. DiFiglia M, Sapp E, Chase K, Schwarz C et al. Huntingtin is a cytoplasmic protein associated with vesicles in human and rat brain neurons. Neuron, 1995; 14:1075-1081.

4. Enmark E, Pelto-Huikko M, Grandien K, Lagercrantz S, Lagercrantz J, Fried G, Nordenskjold M, Gustafsson JA. Human estrogen receptor $\beta$-gene structure, chromosomal localization, expression pattern. Journal of Clinical Endocrinology and Metabolism 1997; 82:4258-4265.

5. Geistlinger TR, McReynolds AC, Guy KR. Ligand-selective inhibition of the interaction of steroid receptor coactivators and estrogen receptors isoforms. Chemistry and Biology, 2004; 11:273-281.

6. Greenstein B, Greeinstein A. Color Atlas of Neuroscience: Neuroanatomy and Neurophysilogy. Sttutgart: Thieme SRN, 2000. p. 296. 
7. Gustafsson AJ. Estrogen receptor $\beta$ - a new dimension in estrogen mechanism of action. Journal of Endocrinology, 1999; 163:379383.

8. Hart SA, Patton JD, Woolley CS. Quantitative analysis of ER alpha and GAD colocalization in the hippocampus of the adult female rat. J Comp Neurol. 2001; 440:144-55.

9. Hoon R. Estrogen Regulation of Mitochondrial Transcription in HD. Boston University Medical Campus, dept. Of neurology and National Institute of Neurological Disorders and Stroke. [serial on the internet]. April 2006 [cited 2007 March], about 1p. Available from: http://researchresources.bumc.bu.edu/abstract/ 1R01NS052724-01.htm

10. Steroid hormone receptors. [serial on the internet]. Sept. 2006 [cited March 2007]. Available from: http://www.neurosci.pharm. utoledo.edu/MBC3320/steroids.htm.

11. Li H, Wyman T, Yu XZ, Li SH, Li JX. Abnormal association of mutant huntingtin with synaptic vesicles inhibits glutamate release. Human Molecular Genetics, 2003; 16:2021-2030.

12. Liqin Z, Tzu-Wei W, Roberta DB. Estrogen receptor subtypes alpha and beta contribute to neuroprotection and increased $\mathrm{Bcl}-2$ expression in primary hippocampal neurons. Brain Research, 2004; 1010:22-34

13. Lundholm et al. Gene expression profiling identifies liver X receptor alpha as an estrogen-regulated gene in mouse adipose tissue. Journal of Molecular Endocrinology, 2004; 32:879-892.
14. Luthi-Carter R, Strand A, Peters NL, Solano SM et al. Decreased expression of striatal signaling genes in a mouse model of Huntington's disease. Hum. Mol. Genet., 2000; 9:1259-1271.

15. Marschall J, White K, Weawer M et al. Specific Psychiatric Manifestations Among Preclinical Huntington Disease Mutatio Carriers. ArchNeurol, 2007; 64:116-121.

16. Paxinos G, Franklin KB. The Mouse Brain in Stereotaxic Coordination-CD atlas. The Prince of Wales Medical Research Institute, Australia and McGill University Montreal, Quebec, Canada. San Diego: Academic Press, USA, 2001. ISBN 0-12-547636-1.

17. Pinzone JJ et al. Molecular and Cellular Determinants of Estrogen Receptor $\beta$ Expression. Molecular and cellular biology, 2004; 24:4605-4612.

18. Preiss M, Kučerová H. Neuropsychology in neurology. GradaAvicenum, Praha. 2006, p. 277-280.

19. Rissman EF, Wersinger SR, Fugger HN, Foster TC. Sex with knockout models: behavioral studies of estrogen receptor alpha. Brain Res., 1999; 17:80-90.

20. Sharp AH, Loev SJ, Schilling G, Li SH, Li XJ, Bao J et al. Widespread expression of Huntington's disease gene (IT15) protein product. Neuron, 1995; 14:1065-1074. 